\title{
A study of prevalence of microalbuminuria in recently detected type 2 diabetes and its relation to hypertension, dyslipidaemia and obesity
}

\author{
Shrikrishna V Acharya \\ Consultant Endocrinologist, K S Hegde Medical Academy, Mangalore, India
}

Background: Microalbuminuria is one of the earliest markers of diabetic nephropathy, and if not recognized and treated early it may lead to diabetic nephropathy resulting in chronic renal failure. Aims and Objective: The aim of the current study was to find out the prevalence of microalbuminuria among newly detected Type 2 diabetic patients and also compare prevalence of microalbuminuria in patients with or without hypertension, dyslipidaemia and obesity.Materials and Methods: In this retrospective study, we analysed 90 patients with new onset type 2 diabetes mellitus. We divided the patients into two groups, group 1 with comorbidities like hypertension, dyslipidaemia and obesity (50 patients) and group 2 without comorbidities (40 patients). We analysed urinary microalbumin level in all patients and compared the prevalence of microalbuminuria between group 1 and group 2. Results: In our cohort of 90 patients, urinary microalbuminuria was found in 30 patients $(33.3 \%)$. When we divided these nephropathy patients to group 1 and group 2, we observed that group 1 with comorbidities had higher percentage of nephropathy patients i.e 24 out of $50(48 \%)$. Group 2 with 40 patients had only 6 patients with microalbiminuria ie 6 out of $40(15 \%)$. Incidence of microalbiminuria was higher in patients with hypertension, dyslipidaemia and obesity. Conclusions: We conclude that incidence of microalbiminuria is much more common in newly diagnosed type 2 diabetes. We also conclude that hypertension, obesity and hypercholesterolemia are risk factors for nephropathy and urinary microalbuminuria appears to be much more sensitive than serum creatinine as screening tool to detect diabetic nephropathy.

Key words: Diabetic nephropathy; Hypertension; Hypercholesterolemia; Microalbuminuria
Access this article online

\section{Website:}

http://nepjol.info/index.php/AJMS

DOI: 10.3126/ajms.v11i5.29402

E-ISSN: 2091-0576

P-ISSN: 2467-9100

Copyright (c) 2020 Asian Journal of Medical Sciences

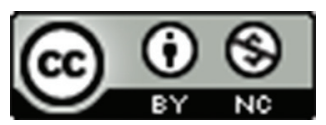

This work is licensed under a Creative Commons Attribution-NonCommercial 4.0 International License.

\section{INTRODUCTION}

Diabetes Mellitus (DM) is one of the most common non communicable diseases in developed nations. But now a days it is becoming very common in developing countries, may be because of change in lifestyle and economic prosperity. India is second only to China in number of diabetes cases and has been rightly called "Diabetes capital of the world. If number increases in the same pattern, number of patients with diabetes expected to cross 79.4 million by year $2030 .{ }^{1}$
By the time patient is diagnosed to have diabetes, he/she is already developed complications like diabetic nephropathy, retinopathy and neuropathy, so rightly called the silent killer. In India diagnosis is usually delayed compared to developed nations may be due to ignorance, delayed presentation, alternative forms of treatment and lack of facilities in rural area. Microalbuminuria, may start very early in the disease and is one of the first markers for diabetic nephropathy and is an independent risk factor for development of cardiovascular complications. Microalbuminuria is defined as the excretion of $30-300 \mathrm{mg}$ of albumin per 24 hours or 
$30-300 \mathrm{mcg} / \mathrm{mg}$ creatinine in spot urine sample. ${ }^{2}$ Albumin below $30 \mathrm{mg}$ per 24 hours or less than $30 \mathrm{mcg} / \mathrm{gm}$ of creatinine is considered as normoalbuminuria. We know that diabetic nephropathy and microalbuminuria are one of the strong predictors of cardiovascular and overall morbidity and mortality in patients of diabetes, and hence we need to give importance to early detection of same. Usually urinary microalbuminuria represents a more generalized vascular damage than just renal microvascular damage alone. We have noticed exponential increase in number of patients with end stage renal disease in last decade due to increase in incidence of diabetes. About $30 \%$ type 2 diabetic patients with microalbuminuria progress to overt nephropathy if no treatment is given. ${ }^{2}$ The mortality rate in patients with proteinuria found to be 40 times more compared to patient without proteinuria and diabetic patient with renal disease has 17 times higher mortality rate compared to non-diabetic person. ${ }^{3}$ It was proved that patients of Asian origin (52.6\%) have more prone to develop diabetic end stage renal disease compared to Caucasian population (36.2\%). Many research papers found that incidence and prevalence of nephropathy varies between geographic locations and ethnicity like they have shown that risk is more in Mexican Americans, Asians, Pima Indians and African people. ${ }^{4}$

Urinary microalbuminuria is an important clinical parameter since early diagnosis and treatment at this stage can revert the pathological process in the kidney to normal. This is more important in India because diagnosis of diabetes is much more delayed in India compared to western world. A study is indicated to find out what is the prevalence of diabetic microalbuminuria, what are the risk factors and if targeting these factors benefit the patients or not. Hence, this study aims at determining the prevalence of urinary microalbuminuria and impact of risk factors like Hypertension, Obesity and Hypercholesterolemia on albuminuria.

Objective of this study were to find the prevalence of microalbuminuria in newly detected Type $2 \mathrm{DM}$ patients and to study the effect of Hypertension, Hypercholesterolemia and Obesity on prevalence of microalbuminuria in these group of patients.

\section{MATERIALS AND METHODS}

This was a retrospective study carried out from October 2016 to September 2018 at K S Hegde Medical College and speciality hospital, a tertiary care referral centre. We had total 90 patients enrolled for the study out of which 49 patients were male and 41 were female. The mean age was 49.24 years, with 28 being the youngest and 70 being the oldest.
The criteria for diagnosing DM are the same as given by WHO and ADA based on oral Glucose Tolerance Test is as follows. ${ }^{2}$

A fasting plasma glucose (FPG) level of $126 \mathrm{mg} / \mathrm{dL}$ $(7.0 \mathrm{mmol} / \mathrm{L})$ or higher, or

A 2-hour plasma glucose level of $200 \mathrm{mg} / \mathrm{dL}$ (11.1 mmol/L) or higher during a 75 -g oral glucose tolerance test (OGTT), or

A random plasma glucose of $200 \mathrm{mg} / \mathrm{dL}(11.1 \mathrm{mmol} / \mathrm{L})$ or higher in a patient with classic symptoms of hyperglycaemia or hyperglycemic crisis, or

\section{A haemoglobin A1c (HbA1c) level of $6.5 \%(48 \mathrm{mmol} / \mathrm{mol})$} or higher

We have divided the patients in 2 groups. Group 1: Diabetic patients with hypertension and/or obesity and/or hypercholesterolemia (50 patients). Group 2: Diabetic patients without any of the above-mentioned factors (40 patients).

The inclusion criteria of selection of subjects were as followsAge more than 20 years. Newly detection of diabetes or within 6 months at the time of enrolment in study.

The exclusion criteria was- Patients having type 1 diabetes of less than 20 years of age with primary and secondary renal diseases. Also patients with fever, pregnant women, urinary tract infection, congestive cardiac failure, and known case of diabetes for more than 6 months were excluded. Those patients already detected to having renal failure, Hypertensive with ACE inhibitors or angiotensin receptor blockers were also excluded from the study.

\section{Parameters recorded}

Microalbuminuria can be diagnosed from a 24-hour urine collection (between $30-299 \mathrm{mg} / 24$ hours) or, more commonly, from elevated concentrations in a spot urine sample (30 to $299 \mathrm{mg} / \mathrm{L}$ ) as done by us.

A complete history, clinical examination and investigation profile were copied from the medical records of all these patients.

BMI (Body Mass Index): BMI was measured by the formula of dividing weight in $\mathrm{kgs}$ by height in meter square. Patient were classified based on BMI into 4 groups ${ }^{5}$

$$
\text { BMI }(\mathrm{Kg} / \mathrm{m} 2) \quad \leq 18.4 \text { - Underweight }
$$

18.5-22.9 - Normal

23-24.9- Over weight

$>25$-Obese 
Hypertension:- When there was a history of hypertension, drug therapy for the hypertension or blood pressure recorded was more than $140 / 90 \mathrm{mmHg}$ on 3 consecutive occasions. ${ }^{5}$ Complete lipid profile was done for hypercholesterolemia. Then author studied both the groups for prevalence of diabetic nephropathy and analysed if there was a statistical difference in between these groups and inside the group 1 itself.

Blood sugar Control was graded based on HbA1c level as follows ${ }^{6,7}$ :

Good control: HbA1c $<7$

Fair control: HbA1c 7-8

Poor control: HbA1C $>8$

Criteria for diagnosis of dyslipidaemia ${ }^{2}$

Total Cholesterol - more than $200 \mathrm{mg} / \mathrm{dL}$

Low-density lipoproteins (LDL) - more than $100 \mathrm{mg} / \mathrm{dL}$ Triglycerides - more than $150 \mathrm{mg} / \mathrm{dL}$

High-density lipoproteins (HDL) Less than $40 \mathrm{mg} / \mathrm{dL}$ in male and less than 50 in female

Statistical analysis: The statistical analysis was carried out using Statistical Package of Social Science (SPSS 2015). All quantitative variables were estimated using measures mean and standard deviation. Student 's t test was used to compare means between two groups. $P$ value was considered significant at a level of $<0.01$. We obtained institutional ethical committee permission for the study.

\section{RESULTS}

In this study, out of 90 total patients, 30 patients were detected to have Diabetic nephropathy (33.3\%). In group 1 , out of 50 patients $24(48 \%)$ patients had diabetic nephropathy, while in group 2; out of 40 patients $6(15 \%)$ patients had diabetic nephropathy (Table 1).

A subgroup analysis was done within Group 1 with regards to multiple co-morbidities, showing increasing number of patients affected with increasing co morbidities (Table 2).

Hypertension was found in 53\% of patients with microalbuminuria where as it was found in only $10 \%$ of patients without microalbuminuria (Table 2). Dyslipidaemia was seen in $60 \%$ patients, while obesity was seen in $70 \%$ of patients with microalbuminuria. In patients without microalbuminuria it was $15 \%$ and $25 \%$ respectively for dyslipidaemia and obesity. Thus, our study confirms that patients with comorbidities like hypertension, dyslipidaemia and obesity have higher probability of developing nephropathy compared to patients without these comorbidities.
The data shows (Table 3 ) that more than $50 \%$ of patients had HbA1c level of more than 8 at the time of presentation. Only one patient with $\mathrm{HbA1c}<7$ had microalbuminuria $(10 \%)$. In the group were $\mathrm{HbA1c}$ was between 7-8, we had 6 patients with microalbuminuria (21.4\%). But patient with $\mathrm{HbA1c}>8$, we had 24 patients with microalbuminuria (46.1\%). This confirms that patients with uncontrolled diabetes are more prone to develop microalbuminuria hence nephropathy. The data (Table 3) also shows that maximum number of $(80 \%)$ patients with microalbuminuria are having their $\mathrm{HbA} 1 \mathrm{c}>8$ and was statistically significant $(\mathrm{p}<0.05)$.

Both mean systolic and mean diastolic blood pressure were in linear relationship with urinary albumin level and were found to be statistically significant $(\mathrm{P}<0.01)$ (Table 4). This proves that patient with higher systolic and diastolic blood pressure are more likely to develop microalbuminuria compared to normal blood pressure.

The above table shows that patients with higher BMI have higher probability of developing microalbuminuria

\begin{tabular}{|c|c|c|c|}
\hline & $\begin{array}{c}\text { Group } 1 \\
\text { (50patients) }\end{array}$ & $\begin{array}{c}\text { Group } 2 \\
\text { (40 patients) }\end{array}$ & $\begin{array}{c}\text { Total } \\
\text { patients }\end{array}$ \\
\hline With nephropathy & $24(48 \%)$ & $6(15 \%)$ & 30 \\
\hline Without nephropathy & 26 & 34 & 60 \\
\hline Total patients & 50 & 40 & 90 \\
\hline
\end{tabular}

\begin{tabular}{|c|c|c|c|}
\hline & Hypertension & Dyslipidaemia & Obesity \\
\hline Microalbuminuria (30) & $16(53.3 \%)$ & $18(60 \%)$ & $21(70 \%)$ \\
\hline No Microalbuminuria (60) & $6(10 \%)$ & $9(15 \%)$ & $15(25 \%)$ \\
\hline
\end{tabular}

\begin{tabular}{|c|c|c|c|c|}
\hline HbA1c & normoalbuminuria & microalbuminuria & $\begin{array}{c}\text { Total } \\
\text { no }\end{array}$ & $P$ value \\
\hline$<7$ & 10 & 1 & 11 & \\
\hline $7-8$ & 22 & 5 & 28 & \\
\hline$>8$ & 28 & 24 & 52 & $<0.05$ \\
\hline Total & 60 & 30 & 90 & \\
\hline
\end{tabular}

\begin{tabular}{|c|c|c|c|}
\hline $\begin{array}{l}\text { Blood } \\
\text { pressure }\end{array}$ & Normoalbuminuria & Microalbuminuria & $P$ value \\
\hline $\begin{array}{l}\text { Mean systolic } \\
\mathrm{BP}(\mathrm{mmHg})\end{array}$ & $123.57 \pm 10.4$ & $137.69 \pm 10.57$ & $<0.05$ \\
\hline $\begin{array}{l}\text { Mean diastolic } \\
\mathrm{BP}(\mathrm{mmHg})\end{array}$ & $77.4 \pm 5.87$ & $84.47 \pm 6.96$ & $<0.05$ \\
\hline
\end{tabular}


compared to normal BMI patients (Table 5). The difference was shown to be statistically significant $(\mathrm{P}<0.01)$. This shows that obesity is an independent risk factor for development of albuminuria

Table 6 shows that mean total cholesterol and LDL cholesterol are higher in patients with microalbuminuria when compared to normoalbuminuria and was found statistically significant. Though triglyceride level was higher in macroalbuminuric patients, it was not statistically significant. The findings (Table 6) reiterates the fact that control of dyslipidaemia is of paramount important in reducing the complications of diabetes especially nephropathy.

We also found that few patients had elevated creatinine level along with microalbuminuria. This proves that patient may present with renal failure at the time of diagnosis of diabetes mellitus.

\section{DISCUSSION}

Diabetic nephropathy is a dreaded complication of diabetes mellitus and early detection is of paramount importance. In this study, out of 90 total patients, total 30 patients were detected to have diabetic nephropathy ie prevalence is $33.3 \%$. In group 1 with comorbidities like hypertension, dyslipidaemia and obesity, out of 50 patients 24 (48\%) patients had diabetic nephropathy, while in group B, out of 40 patients only $6(15 \%)$ had diabetic nephropathy

In Table 7 , we can see that prevalence of diabetic nephropathy varies from $15 \%$ to $54 \%$ in different studies. The variation in prevalence may be due to ethnicity, method of collection of urine albumin, number of collections, other illness, and study methodology, number of patients with hypertension, obesity and dyslipidaemia. Relatively higher prevalence of diabetic nephropathy detected in this study may be due to many reasons like ignorance of general public and delayed presentation to physician. These factors responsible for late diagnosis of DM and patient will be suffering from diabetes without treatment for years which ultimately result in higher prevalence diabetic nephropathy.

In this study, we found 24 out of 50(48\%) patients in Group 1 (those having hypertension and/or hypercholesterolemia and/or obesity) to have diabetic nephropathy. While in Group B (without any of the 3 factors), only 6 out of $40(15 \%)$ patients were detected to have diabetic nephropathy.

The microalbuminuric patients had significantly increased systolic and diastolic blood pressure compared to

$\begin{aligned} & \text { Table } 5 \text { : BMI in relation to urinary } \\
& \text { microalbuminuria }\end{aligned}$
\begin{tabular}{lccc}
\hline & Microalbuminuria & Normoalbuminuria & P value \\
\hline $\mathrm{BMI}$ & $26.5 \pm 3.7$ & $24.2 \pm 2.6$ & $<0.01$ \\
\hline
\end{tabular}

\begin{tabular}{lccc}
\multicolumn{4}{l}{ Table 6: Lipid profile in patients microalbuminuria } \\
\hline $\begin{array}{l}\text { Lipid } \\
\text { profile }\end{array}$ & Microalbuminuria & Normoalbuminuria & P value \\
\hline $\begin{array}{l}\text { Total } \\
\text { cholesterol }\end{array}$ & $193.4 \pm 49.6$ & $170.5 \pm 39.1$ & $<0.01$ \\
LDL & $125.7 \pm 40.3$ & $101.2 \pm 30.7$ & $<0.01$ \\
Triglyceride & $165.7 \pm 48.6$ & $144.8 \pm 45.7$ & $\begin{array}{c}\text { Not } \\
\text { significant }\end{array}$ \\
\hline
\end{tabular}

\begin{tabular}{|c|c|c|}
\hline Author & Year of study & Prevalence \\
\hline Niskanen et $\mathrm{al}^{8}$ & 1990 & $19 \%$ \\
\hline Yajnik et al ${ }^{9}$ & 1992 & $23 \%$ \\
\hline Ghai et al ${ }^{10}$ & 1994 & $25 \%$ \\
\hline Cathelineau et al ${ }^{11}$ & 1997 & $29.6 \%$ \\
\hline Vijay et $\mathrm{al}^{12}$ & 1998 & $21 \%$ \\
\hline Viberti et $a^{13}$ & 2002 & $15.2 \%$ \\
\hline Sosenko et al ${ }^{14}$ & 2002 & $18 \%$ \\
\hline Annemieke et $\mathrm{al}^{15}$ & 2003 & $26.7 \%$ \\
\hline Unuigbe et al ${ }^{16}$ & 2004 & $49.2 \%$ \\
\hline Chowta N K et al ${ }^{17}$ & 2009 & $37 \%$ \\
\hline Bhashkar et al ${ }^{18}$ & 2011 & $54,09 \%$ \\
\hline Debbarma et a $\left.\right|^{19}$ & 2015 & $20.19 \%$ \\
\hline Vitan patel et al ${ }^{20}$ & 2018 & $43 \%$ \\
\hline Present study & 2020 & $33.3 \%$ \\
\hline
\end{tabular}

normoalbuminuric subjects $(\mathrm{P}<0.01)$. John et $\mathrm{al}^{21}$ reported that male gender, elderly, longstanding diabetes, uncontrolled blood sugar and elevated blood pressure as risk factors of microalbuminuria. Agarwal et al ${ }^{22}$ reported that diabetes patients with hypertension have $60 \%$ chance of development of nephropathy. Another study by Vijay et $\mathrm{a}^{12}$ showed that duration of diabetes, blood pressure, age of the patient, and serum creatinine to be associated with proteinuria

This study also proves that patients with higher HbA1c at the time of presentation had higher prevalence of nephropathy $(\mathrm{P}<0.01)$. Patients with HbA1c $>8$ had $46.1 \%$ prevalence of microalbuminuria. A study by Gupta et $\mathrm{al}^{22}$ showed that patients with higher $\mathrm{HbA} 1 \mathrm{c}$ had higher incidence of diabetic nephropathy.

In our study mean BMI of normoalbuminuric patients was $24.2 \pm 2.6 \mathrm{~kg} / \mathrm{m}^{2}$ and that of microalbuminuric patients was $26.5 \pm 3.7 \mathrm{~kg} / \mathrm{m}^{2}$. Therefore, it is beyond doubt that obese patients have higher incidence of microalbuminuria. Kohler et al showed that increased risk of microalbiminuria is 
seen in patients with poor glycemic control, endogenous hyperinsulinemia, high blood pressure, elevated triglyceride levels, and obesity. ${ }^{23}$ Thus, we conclude that diabetic patients with risk factors of hypertension and/or obesity and/or hypercholesterolemia are at a much greater risk of developing diabetic nephropathy, at the onset. Even without the risk factors, we found that the prevalence of microalbuminuria at onset of type 2 diabetes mellitus was $15 \%$, which cannot be ignored. While the $48 \% \%$ prevalence associated with these risk factors is also to be taken with great concern. We need to educate the general public, medical fraternity and government regarding early diagnosis and treatment to address this problem.

Our study has many drawbacks. Firstly, small sample size, retrospective in nature makes this study less powerful to do complete subgroup analysis of every risk factor associated with nephropathy. Further studies are needed to find out importance of each risk factor and combination of different factors on nephropathy prevalence.

This highlights the importance of performing the urinary micro albumin in all patients at the time of diagnosis and it may be the most sensitive tool to diagnose incipient diabetic nephropathy. This also brings to our notice, the common practice of doing only creatinine at diagnosis and follow up of patients with diabetes to assess renal function.

\section{CONCLUSION}

We conclude that micro albuminuria is important predictor of diabetic nephropathy and is reasonably high at the onset of diabetes mellitus. Our study also showed that its prevalence is high in type $2 \mathrm{DM}$ with those associated comorbidites like hypertension, obesity and dyslipidemia.

\section{ACKNOWLEDGEMENT}

The authors would like to acknowledge K S Hegde medical Academy, Mangalore to allow me to carry out the present study.

\section{REFERENCES}

1. Kaveeshwar SA and Cornwall J. The current state of diabetes mellitus in India. Australasian Medical Journal. 2014;7:45-48. https://doi.org/10.4066/AMJ.2014.1979

2. American Diabetes Association. Diagnosis and classification of diabetes mellitus. Diabetes Care 2014; 37(Suppl. 1):S81-S90. https://doi.org/10.2337/dc14-S081

3. Alberti KGMM. Problems related to definitions and epidemiology of type 2 DM. Diabetologia. 1993; 36; 948-984.

https://doi.org/10.1007/BF02374487
4. Nelson RG, Knowler WC, Pettitt DJ, Saad MF and Bennett PH. Diabetic kidney disease in Pima Indians. Diabetes Care.1993; 16:335-341.

https://doi.org/10.2337/diacare.16.1.335

5. Misra A, Chowbey P and Makkar BM. Consensus statement for diagnosis of obesity, abdominal obesity and the metabolic syndrome for Asian Indians and recommendations for physical activity, medical and surgical management. J Assoc Physicians India. 2009; 57:163-170.

6. Daskalopoulou SS, Khan NA and Quinn RR. The 2012 Canadian Hypertension Education Program (CHEP) recommendations for the management of hypertension: Blood pressure measurement, diagnosis, assessment of risk and therapy. Can J Cardiol. 2012; 28:1-38.

7. Rodr'lguez-Segade S, Rodr'Iguez J, Mayan D and Cami F. Plasma Albumin Concentration Is a Predictor of HbA1c Among Type 2 Diabetic Patients, Independently of Fasting Plasma Glucose and Fructosamine. Diabetes Care. 2005; 28(2). https://doi.org/10.2337/diacare.28.2.437

8. Niskanen, Uusitupa M, Sarlund H, Siitonen O, Voutilainen E, Penttila I, et al. Microalbuminiuria predicts the development of serum lipoprotien abnormalities favouring atherogenesis in newly diagnosed Type 2 (noninsulin-dependent) diabetic patients. Diabetologia. 1990: 33: 237-243. https://doi.org/10.1007/BF00404802

9. Yajnik CS, Naik SS, Raut KN, Khade AD, Bhat DS, Nagarkar VD, et al. Urinary albumin excretion rate (AER) in newly diagnosed Type 2 Indian diabetic patients is associated with central obesity and hyperglycaemia. Diab Res and Clin Prac. 1992; 17: 55-60. https://doi.org/10.1016/0168-8227(92)90044-R

10. Ghai R, Verma ND, Goel A, Bhatnagar MK, Kapoor P and Vashishta A. Microalbuminuria in noninsulin dependent Diabetes and essential hypertension: A marker of severe disease. J Assoc Physicians India. 1994;42:771-774.

11. Cathelineau G, de Champvallins M, Bouallouche A and Lesobre B. Management of newly diagnosed non-insulindependent diabetes mellitus in the primary care setting: effects of 2 years of gliclazide treatment--the Diadem Study. Metabolism. 1997;46(12 Suppl 1):31-34 https://doi.org/10.1016/S0026-0495(97)90314-0

12. Viswanathan V, Seena R, Lalitha S, Snehalata C, Muthu J and Ramachandran A, Significance Of Microalbuminuria At Diagnosis Of Type 2 Diabetes, Int J Diab Dev Countries. 1998; Vol. 18.

13. Viberti G, Freed MI, Holman R, Lachin J, Heise MA and The ADOPT Study Group; Prevalence of Microalbuminuria in Recently Diagnosed Type 2 Diabetes Mellitus and its Relationship to Non-Traditional Risk Factors: Observations from the ADOPT Study, Diabetes Care. 2002; 25(10). https://doi.org/10.2337/diacare.25.10.1737

14. Sosenko JM, Songsheng Hu, Welty T, Howard BV, Lee E and Robbins DC. Albuminuria in Recent-Onset Type 2 Diabetes, The Strong Heart Study, Diabetes Care. 2002; (51):6. https://doi.org/10.2337/diacare.25.6.1078

15. Spijkerman AMW, Dekker JM, Nijpels G, Adriaanse MC, Kostense PJ, Ruwaard D, et al. Microvascular Complications at Time of Diagnosis of Type 2 Diabetes Are Similar Among Diabetic Patients Detected by Targeted Screening and Patients Newly Diagnosed in General Practice , The Hoorn Screening Study, Diabetes Care. 2003; 26(9). https://doi.org/10.2337/diacare.26.9.2604

16. Unuigbe $\mathrm{El}$, Omeife $\mathrm{H}$, Edema T and Ukoli FA. Microalbuminuria and associated factors in newly diagnosed diabetics. Niger Postgrad Med J. 2001;8(4):187-192. 
17. Chowta NK, Pant $P$ and Chowta MN. Microalbuminuria in Diabetes mellitus: Association with age, sex, weight, and creatinine clearance. Indian J Nephrol. 2009; 19:53-56.

https://doi.org/10.4103/0971-4065.53322

18. Thakkar B, Arora K, Vekariya R, Lulania M and Agnihotri AS Prevalence of Microalbuminuria in Newly Diagnosed Type 2 Diabetes Mellitus. National Journal of Integrated Research in Medicine. 2011; 2(4).

19. Debbarma B, Debbarma $R$ and Pegu AK. Significance of Microalbuminuria in Newly Diagnosed type 2 Diabetes Mellitus. IOSR Journal of Dental and Medical Sciences. 2015; 14(8): 40-47.

20. Patel V, Shastri M, Gaur N, Jinwala P and Abhishek Y. A study in prevalence of diabetic nephropathy in recently detected cases of type 2 diabetes mellitus as evidenced by altered creatinine clearance, urinary albumin and serum creatinine, with special emphasis on hypertension, hypercholesterolemia and obesity. Kadam International Journal of Advances in Medicine. 2018; 5(2):351-355. https://doi.org/10.18203/2349-3933.ijam20180999

21. John L, Rao PS and Kanagasabapathy AS. Prevalence of diabetic nephropathy in non-insulin dependent diabetes. Indian J Med Res. 1991;94:24-29.

22. Agarwal N, Sengar NS and Jain PK. Nephropathy in newly diagnosed type 2 Diabetics with special stress on the role of Hypertension. JAPI. 2011; 59:145-147.

23. Kohler KA, McClellan WM, Ziemer DC and Kleinbaum DG, Boring JR. Risk factors for microalbuminuria in black americans with newly diagnosed type 2 diabetes. Am J Kidney Dis. 2000; 36(5):903-913.

https://doi.org/10.1053/ajkd.2000.19080

\section{Authors Contribution:}

SVA - Concept and design of the study; interpreted the results, prepared the manuscript and critical revision of the manuscript, statistically analyzed, interpreted, reviewed the literature:

Work attributed to:

Department of Endocrinology, K S Hegde Medical Academy Mangalore

\section{Orcid ID:}

Dr. Shrikrishna. V. Acharya - (1) https://orcid.org/0000-0002-9584-7209 